\title{
Relação entre parâmetros ecológicos e qualidade ambiental em três córregos na bacia do alto rio Paraná
}

\author{
Fagner de Souza ${ }^{1,2 *}$ \\ Jéssica Aline Soares de Abreu ${ }^{2}$ \\ Carlos Eduardo da Silva ${ }^{3}$ \\ Ariane Aparecida Gouveia ${ }^{4}$ \\ ${ }^{1}$ Universidade Estadual de Maringá, PPG em Biologia Comparada \\ ${ }^{2}$ Coleção Ictiológica do Núcleo de Pesquisa em Limnologia, Ictiologia e Aquicultura \\ Avenida Colombo, 5790, CEP 87020-900, Maringá - PR, Brasil \\ ${ }^{3}$ Universidade Tecnológica Federal do Paraná, PPG em Tecnologia de Alimentos, Campus Londrina \\ ${ }^{4}$ Universidade Tecnológica Federal do Paraná, Especialização em Gestão Ambiental em Municípios Campus Medianeira \\ * Autor para correspondência \\ gnaofagner@hotmail.com
}

Submetido em 03/03/2013

Aceito para publicação em 04/09/2012

\section{Resumo}

Os ambientes aquáticos frequentemente vêm sofrendo grandes distúrbios ambientais, e medidas alternativas para conservação da biodiversidade devem ser tomadas para impedir a redução da riqueza de espécies em ambientes impactados. Diante disso, partimos da hipótese que entre córregos naturais e impactados há diferenças na correlação entre os parâmetros ecológicos e qualidade ambiental. Realizamos o levantamento da assembleia de peixes em três córregos na bacia do alto rio Paraná, relacionando em cada córrego as estruturas ecológicas com a qualidade ambiental. Comparações entre a integridade ambiental e parâmetros ecológicos foram realizadas. Foram coletados 8.028 indivíduos distribuídos em três ordens, seis famílias, nove gêneros e 11 espécies. Baixos valores nos índices ecológicos junto com a baixa qualidade de hábitats foram encontrados em um dos córregos (córrego Japira), e este fato pode ser devido à grande quantidade de residências no seu entorno, que pode estar favorecendo a degradação da complexidade ambiental. Estes fatos indicam que medidas de restauração, como ações de reestruturação da mata ciliar e aplicação de programas de educação ambiental, devem ser aplicadas para recuperação e preservação ambiental destas áreas.

Palavras-chave: Assembleia de peixes; Impactos ecológicos; Rio Ivaí; Rio Pirapó; Rio Tibagi

\section{Abstract}

Relationship between ecological parameters and environmental quality of three streams in the upper Paraná River basin. Aquatic environments frequently suffer great environmental disturbances, and alternative actions for biodiversity conservation must be taken to prevent the reduction of species richness in areas impacted. Given this, we started with the hypothesis that among natural and impacted streams, there are differences in the correlation between ecological parameters and environmental quality. The fish assemblages in three streams in the upper Paraná River basin were surveyed, and for each stream the ecological structures were related to environmental quality. Comparisons between the environmental integrity and ecological parameters 
were made. We collected 8,028 individuals, distributed in 3 orders, 6 families, 9 genera and 11 species. Low values in ecological indexes together with low habitat quality were found for one of the streams (Japira Stream). This is probably because there are a large number of residences in the surrounding area that are degrading the environmental complexity. These facts indicate that restoration measures, such as restructuring the riparian vegetation and offering environmental education programs, must be initiated to promote the recovery and environmental preservation of these areas.

Key words: Fish assemblage; Ecological impacts; Ivaí River; Pirapó River; Tibagi River

\section{Introdução}

A Região Neotropical possui uma das maiores diversidades de peixes de água doce do mundo, com uma riqueza de aproximadamente 4.500 espécies já conhecidas (LÉVÊQUE et al., 2008). A estrutura da assembleia de peixes de um rio reflete um conjunto de fatores bióticos e abióticos que ocorrem em determinado momento (BENNEMANN et al., 2000;), como a disponibilidade de recursos alimentares, locais de refúgio, eventos biogeográficos e características hidrológicas que atuam como filtros de espécies, estes são fundamentais para que ocorra o estabelecimento de populações aquáticas (ALBERT; REIS, 2011).

Atualmente os ecossistemas aquáticos vêm sofrendo uma variedade de distúrbios ambientais negativos, portanto, medidas alternativas vêm sendo requisitadas em prol da conservação da biodiversidade (RODRIGUES et al., 2010). Neste contexto a redução da riqueza de espécies é relatada em ambientes classificados com baixa qualidade ambiental, tornando este parâmetro um forte indicador das condições ecológicas de ambientes lóticos e lênticos (BARRELLA; PETRERE, 2003). Segundo Karr (1981), a utilização da assembleia de peixes como indicadoras do estado de conservação desses ambientes, permite inferir o grau de equilíbrio entre os componentes do ecossistema.

Dessa forma, os ambientes lóticos devem receber prioridade em sua exploração ecológica (CASTRO; MENEZES, 1998; CASTRO, 1999), especialmente no que diz respeito ao estudo da sistemática, evolução e biologia geral de sua ictiofauna (CASTRO, 1999).

Com isso, levantamos a hipótese de que nos córregos impactados a estrutura da assembleia de peixes é diferente daquela que ocorre em ambientes mais preservados, com tendência a baixos valores na riqueza, e nos índices de diversidade e de equitabilidade de espécies culminado em uma alta dominância e abundância de espécies mais resistentes. Com isso objetivamos promover o levantamento da assembleia de peixes em três córregos na bacia do alto rio Paraná no município de Apucarana-PR, relacionando as estruturas ecológicas de cada córrego com a qualidade ambiental de cada ambiente, a fim de constatar se há um padrão na relação entre a condição do hábitat e os parâmetros ecológicos.

\section{Material e Métodos}

\section{Área de estudo}

O estudo foi realizado na cidade de ApucaranaPR em três córregos (Figura 1) contidos em três bacias hidrográficas diferentes e com características ambientais distintas, descritas em detalhe abaixo. Para cada córrego estipulou-se três pontos trechos (Montante, Médio curso e Jusante), resultando em um total de nove trechos amostrados.

Córrego Jurema: contido na bacia do rio Pirapó, em sua montante $\left(23^{\circ} 33^{\prime} 18.61^{\prime} \mathrm{S} / 51^{\circ} 29^{\prime} 12.51\right.$ 'O) as margens são próximas a residências, apresentando pouca quantidade de mata ciliar (dimensão lateral). $\mathrm{O}$ fluxo de água se alterna em corredeiras e remansos em toda sua extensão, com grande quantidade de rochas de diversos tamanhos e pouca quantidade de sedimento fino. O Médio curso (2333'4.35'S/51²9'13.89”O) sua margem apresenta uma ampla (dimensão lateral e longitudinal) mata ciliar em sua margem proporcionando uma considerável distância entre as residências e o trecho amostrado. Seu fluxo de água tem na maioria regiões de corredeiras e poucos remansos, e seu leito é constituído principalmente por rochas grandes e 
FIGURA 1: Mapa dos trechos de amostragem nos córregos Jurema, Biguaçú e Japira, com marcações de suas bacias hidrográficas (fonte: Quantum GIS versão 1.7.3).

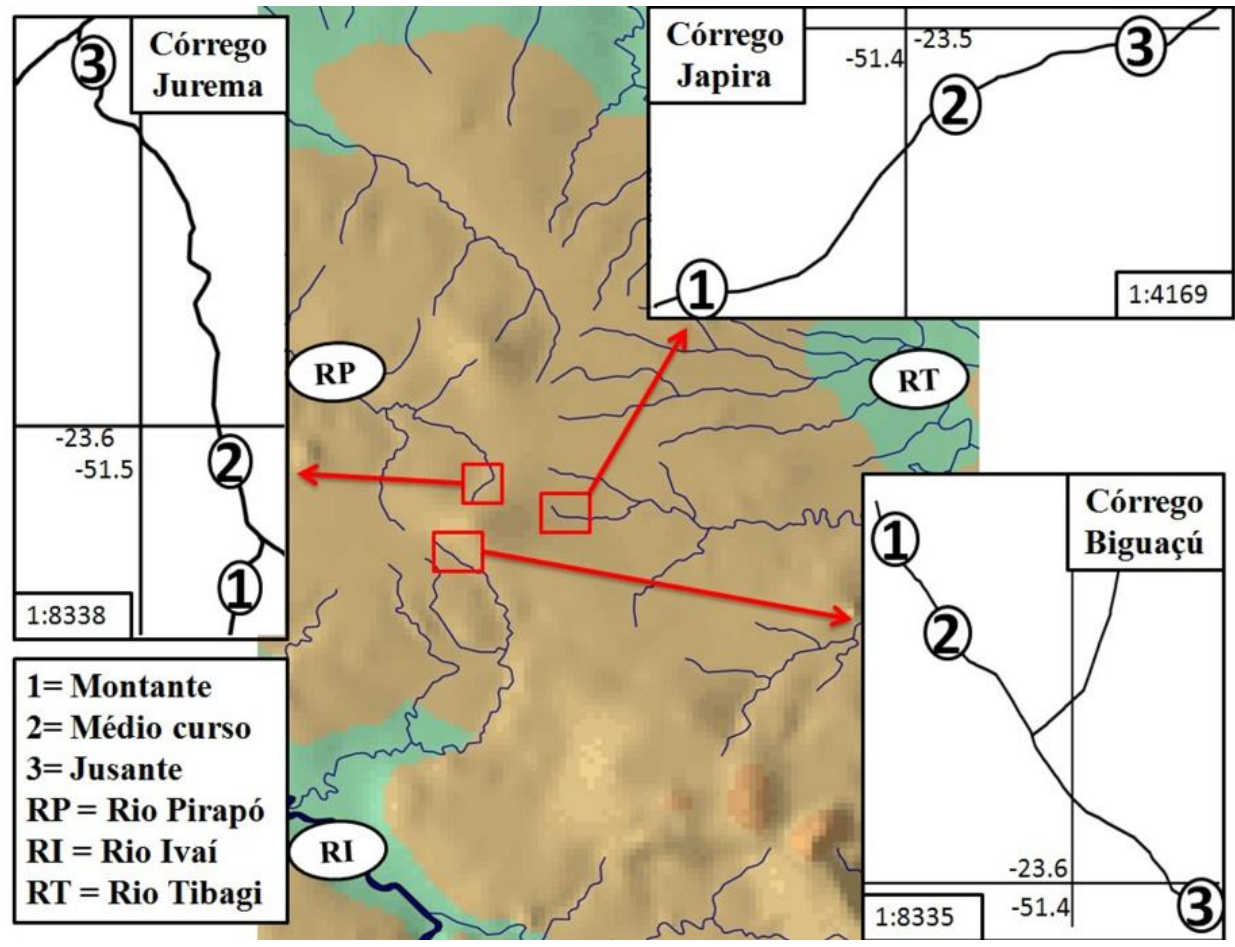

estáveis, com ausência de sedimento. O trecho de Jusante (2332'15.82”S/51²9'30.67’O) possui todo trecho amostrado contido em área rural, com ausência de residências em seu entorno. Suas margens contêm extensa de mata ciliar. Possui fluxo de água diversificado com corredeiras, remansos e poços. Em seu leito há presença de rochas grandes e pequenas, formando seixos e apresentando um solo estável com sedimento fino.

Córrego Biguaçú: contido na bacia do rio Ivaí, sua nascente é encanada e seu fluxo canalizado por um curso cimentado até o trecho de montante amostrado. Em sua montante $\left(23^{\circ} 33^{\prime} 51.81^{\prime \prime} \mathrm{S} / 51^{\circ} 27^{\prime} 2.48^{\prime \prime} \mathrm{O}\right)$ as margens são próximas a residências, e estas são utilizadas pela população como local de despejo de resíduos domésticos. Apresenta pouca densidade de mata ciliar (dimensão lateral), porém o cobre por toda sua extensão (dimensão longitudinal). Seu fluxo de água alterna entre corredeiras e remansos. Seu leito possui grande quantidade de rochas de diversos tamanhos e em alguns locais há presença de sedimento fino e óleo. O

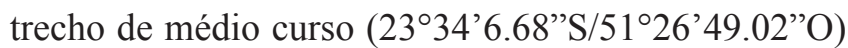

possui a margem localizada em uma região com grande densidade de mata ciliar (dimensão lateral e longitudinal). As corredeiras são predominantes, porém em alguns locais também ocorrem poços. Seu leito é composto de rochas de diversos tamanhos. A Jusante $\left(23^{\circ} 34^{\prime} 52.87^{\prime}\right.$ 'S $/ 51^{\circ} 25^{\prime} 56.79^{\prime \prime}$ ) $)$ a margem é coberta uma densa mata ciliar, com árvores grandes, cobrindo seu trecho em toda sua extensão longitudinal. Possui fluxo de água com corredeiras, remanso e poços. Seu leito é diversificado com presença de rochas grandes e pequenas, formando seixos, e em alguns locais de remanso possui substrato estável e com sedimento fino.

Córrego Japira: contido na bacia do rio Tibagi, possui em sua montante $\left(23^{\circ} 32^{\prime} 58.45^{\prime \prime} \mathrm{S} / 51^{\circ} 26^{\prime} 40.45^{\prime} \mathrm{O}\right)$ as margens estão inseridas totalmente em área urbana, com residências, indústrias e escola em seu entorno. Este trecho apresenta grande degradação da mata ciliar, o solo da margem apresenta-se instável. Seu fluxo de água é de remanso apresentando grande quantidade de lama, gramíneas e em alguns locais apresenta apenas uma camada superficial de água com leito compactado, 
exalando um forte odor provavelmente oriundo de decomposição anaeróbica de matéria orgânica.

O Médio curso (2332’43.80”S/51²6’19.95”O) possui suas margens em região residencial, com presença de resíduos domésticos e apresenta gramíneas por toda sua extensão. O fluxo de água é formado de poços e remansos, no leito há grande quantidade de pequenas rochas com bastante sedimento fino. A Jusante (2332'39.55”S/ 51 ${ }^{\circ} 26^{\prime} 7.18^{\prime}$ 'O) em sua margem direita apresenta residências e em sua margem esquerda áreas de pastagem (gado bovino), composta por gramíneas e em alguns locais não há cobertura vegetal. O fluxo d'água é alternado em corredeiras e poços, com leito estável e presença de pequenas rochas em alguns trechos.

\section{Amostragem ictiológica}

As coletas foram realizadas em quatro campanhas no período de janeiro a novembro de 2012, com intervalos de três meses entre cada campanha, sob licença do Sistema de Autorização e Informação em Biodiversidade - SISBIO (Numero 33448-1). Os peixes foram coletados com peneiras de 1,0x0,50 m e malhas de $3 \mathrm{~mm}$ entre nós adjacentes com esforço amostral de 50 minutos em cada ponto. Após coletados os peixes foram anestesiados (Cloridrato de Benzocaína dissolvido em água, $100 \mathrm{~mL} / 15 \mathrm{~L}$ ), mortos, fixados em formol 10\% e conservados em álcool $70^{\circ} \mathrm{GL}$. Em laboratório, os peixes foram identificados de acordo com Graça e Pavanelli (2007), medidos com a utilização de um paquímetro digital ( $0,1 \mathrm{~mm}$ de precisão), pesados em uma balança de precisão $(0,01 \mathrm{~g}$ de precisão). Exemplares testemunhos foram depositados na Coleção Ictiológica do Núcleo de Pesquisas em Limnologia, Ictiologia e Aquicultura (Nupélia) da Universidade Estadual de Maringá. As categorias taxonômicas superiores foram classificadas de acordo com Eschmeyer (1998), enquanto que as famílias e subfamílias são apresentadas de acordo com Reis et al. (2003) e Mirande (2010)

\section{Análise dos dados}

Os trechos foram avaliados aplicando-se o Protocolo de Avaliação Rápida da Diversidadade de Hábitats que permite classificar os trechos em impactados, alterados e naturais (CALLISTO et al., 2002). Além disso, realizamos comparações espaciais de variáveis biométricas de Comprimento Total (CT), Comprimento Padrão (CP) e biomassa $(\mathrm{g})$, e variáveis bióticas de abundância, curva de rarefação com valores de riqueza de espécies (s), índices de diversidade (H') e equitabilidade (J) de Shannon, e dominância de Simpson (l) de Simpson. Para a curva de rarefação utilizamos o software PAST versão 2.03 (Hammer et al., 2001) e todos os índices foram calculados no software DivEs v. 2.0 (RODRIGUES, 2005). Para comparar a similaridade entre os córregos amostrados utilizamos um dendograma com similaridade de Jaccard, baseado em uma matriz de presença e ausência de espécies, no software PAST versão 2.03 (Hammer et al., 2001).

\section{Resultados}

De acordo com a avaliação de diversidade de hábitats, observamos que o córrego Jurema apresentou melhor qualidade ambiental, apresentando em seu médio curso e jusante qualidade de ambiente natural, e apenas sua montante apresentou condições alteradas. O córrego Biguaçú foi o segundo em ordem de qualidade ambiental, com seu médio curso e jusante considerados naturais e apenas sua montante foi classificada como impactada. Já o córrego Japira foi o riacho que apresentou a pior qualidade ambiental, sendo considerado impactado na sua montante e alterado no médio curso e jusante (Tabela 1).

TABELA 1: Avaliação da diversidade de habitas nos trechos amostrados.

\begin{tabular}{lccc}
\hline \multicolumn{1}{c}{ Local } & Montante & Médio curso & Jusante \\
\hline Córrego Jurema & Alterado & Natural & Natural \\
Córrego Biguaçú & Impactado & Natural & Natural \\
Córrego Japira & Impactado & Alterado & Alterado \\
\hline
\end{tabular}


$\mathrm{Na}$ amostragem ictiológica foram coletados 8.028 indivíduos, distribuídos em três ordens, seis famílias, nove gêneros e 11 espécies (Tabela 2). As ordens mais abundantes foram os Siluriformes com 45,45\%, seguidos de Characiformes $(27,27 \%)$ e Cyprinodontiformes $(18,18 \%)$. As espécies mais abundantes foram Phalloceros harpagos, para os córregos Jurema (43\%) e Japira (52\%), e Astyanax aff. paranae, para o córrego Biguaçú (53\%). As espécies com menores porcentagens de abundância no córrego Jurema foram Rhamdia quelen e Cetopsorhamdia iheringi, ambos obtendo 0,09\% de ocorrência. Já no córrego Biguaçú a espécie Trichomycterus davisi, apresentou $0,21 \%$ de ocorrência, e no córrego Japira a espécie Hypostomus cf. ancistroides com $0,10 \%$ de ocorrência.

TABELA 2: Lista de espécies e classificação sistemática dos peixes coletados nos córregos Jurema, Biguaçú e Japira.

\begin{tabular}{c} 
Osteichthyes \\
Characiformes \\
\hline Characidae \\
Astyanax altiparanae Garutti \& Britski 2000 \\
Astyanax aff. fasciatus (Cuvier 1819) \\
Astyanax aff. paranae Eigenmann 1914 \\
\hline
\end{tabular}

\section{Siluriformes}

Callichthyidae

Corydoras aeneus (Gill 1858)

Loricariidae

Loricariinae

Rineloricaria pentamaculata Langeani \& Araujo 1994

Hypostominae

Hypostomus cf. ancistroides (Ihering 1911)

Heptapteridae

Cetopsorhamdia iheringi Schubart \& Gomes 1959

Rhamdia quelen (Quoy \& Gaimard 1824)

Trichomycteridae

Trichomycterus davisi (Haseman 1911)

Cyprinodontiformes

Poeciliidae

Phalloceros harpagos Lucinda 2008

Poecilia reticulata Peters 1859

As espécies que apresentaram maior porte foram encontradas principalmente no córrego Japira, em ambos os comprimentos (Total e Padrão), com exceção da espécie $A$. aff. paranae no córrego Biguaçú. Em relação às médias de biomassa $P$. reticulata apresentou biomassa semelhante em todos os córregos, já as outras espécies que co-ocorrem apresentaram grande variação entre os córregos, com os maiores valores médios para as espécies $P$. harpagos, $H$. cf. ancistroides no córrego Jurema, $A$. aff. paranae no córrego Biguaçú e $R$. quelen no córrego Japira. Porém, as espécies que apresentaram maiores valores de biomassa total foram às espécies $P$. harpagos, para os córregos Jurema e Japira, e $A$. aff paranae, para o córrego Biguaçú (Tabela 3).

Entre as espécies presentes em todos os ambientes, as que se apresentaram mais abundantes foram $P$. harpagos seguido por $P$. reticulata nos córregos Jurema e Japira, entretanto no córrego Biguaçú a espécie mais abundante foi $A$. aff paranae seguido de $P$. reticulata, todavia diferentemente dos outros córregos a espécie $P$. harpagos obteve pouca abundância no córrego Biguaçú, apresentando apenas seis indivíduos. Algumas das espécies coletadas só foram observadas em dois córregos, este é o caso das espécies Rineloricaria pentamaculata, que ocorreu nos córregos Jurema e Biguaçú, e Corydoras aeneus, com ocorrência nos córregos Jurema e Japira. As espécies Astyanax altiparanae, Cetopsorhamdia iheringi, Astyanax aff. fasciatus só foram encontradas no córrego Jurema e T. davisi apenas no córrego Biguaçú (Figura 2).

Com relação às variáveis da estrutura da ictiofauna, o córrego que apresentou maior riqueza (não significativo, $\mathrm{p}=0,2371$ ) foi o córrego Jurema, com 10 espécies, seguido do córrego Biguaçú, com sete espécies, e o córrego Japira, com seis espécies (Figura 3). Já os córregos com maiores valores nos índices ecológicos (Figura 4) foram o córrego Biguaçú, que obteve maiores valores para os índices de diversidade e equitabilidade de Shannon, e o córrego Japira, que obteve valores altos no índice de dominância de Simpson. Os menores valores apresentados nos índices ecológicos de diversidade, tanto de Shannon como de Simpson, foi no córrego Japira, o índice de equitabilidade no córrego Jurema, e o índice de dominância foi no córrego Biguaçú. 
TABELA 3: Valores dos dados biométricos de Comprimento total (CT), Comprimento Padrão (CP), Média de Biomassa (Bi) e Biomassa total (Bt) nos córregos Jurema, Biguaçú e Japira. Aal (Astyanax altiparanae), Afa (Astyanax aff. fasciatus), Apa (Astyanax aff. paranae), Cae (Corydoras aeneus), Rpe (Rineloricaria pentamaculata), Han (Hypostomus cf. ancistroides), Cih (Cetopsorhamdia iheringi), Rqu (Rhamdia quelen), Tda (Trichomycterus davisi), Pha (Phalloceros harpagos) e Pre (Poecilia reticulata).

\begin{tabular}{|c|c|c|c|c|c|c|c|c|c|c|c|c|}
\hline \multirow{5}{*}{ 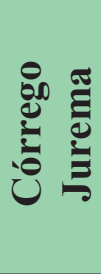 } & & Aal & Afa & Apa & Cae & Rpe & Han & Cih & Rqu & Tda & Pha & Pre \\
\hline & CT & 69,53 & 58,77 & 45,94 & 43,95 & 61,73 & 40,99 & 53,68 & 55,38 & - & 34,3 & 29,86 \\
\hline & $\mathrm{CP}$ & 56,39 & 48,33 & 37,24 & 32,98 & 51,45 & 40,3 & 45,31 & 45,23 & - & 27,78 & 23,43 \\
\hline & $\mathrm{Bi}$ & 5,23 & 2,76 & 1,27 & 1,59 & 1,6 & 4,56 & 1,8 & 1,15 & - & 0,62 & 0,36 \\
\hline & $\mathrm{Bt}$ & 6,92 & 33,16 & 51,01 & 4,57 & 9,82 & 16,44 & 3,6 & 1,15 & - & 105,13 & 21,86 \\
\hline \multirow{4}{*}{ 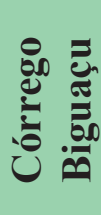 } & $\mathrm{CT}$ & - & - & 57,75 & - & 60,61 & 37,96 & - & 52,95 & 51,99 & 24,65 & 30,68 \\
\hline & $\mathrm{CP}$ & - & - & 46,94 & - & 52,14 & 29,52 & - & 43,95 & 46,77 & 19,95 & 23,79 \\
\hline & $\mathrm{Bi}$ & - & - & 3,31 & - & 0,91 & 0,64 & - & 1,43 & 1,13 & 0,16 & 0,42 \\
\hline & $\mathrm{Bt}$ & - & - & 73,8 & - & 3,9 & 1,66 & - & 9,44 & 1,13 & 0,38 & 12,86 \\
\hline
\end{tabular}

FIGURA 2: Abundância de espécies nos córrego Jurema, Biguaçú e Jurema. Tda (Trichomycterus davisi), Afa (Astyanax aff. fasciatus), Cih (Cetopsorhamdia iheringi), Aal (Astyanax altiparanae), Cae (Corydoras aeneus), Rpe (Rineloricaria pentamaculata), Apa (Astyanax aff. paranae), Han (Hypostomus cf. ancistroides), Rqu (Rhamdia quelen), Pha (Phalloceros harpagos) e Pre (Poecilia reticulata).

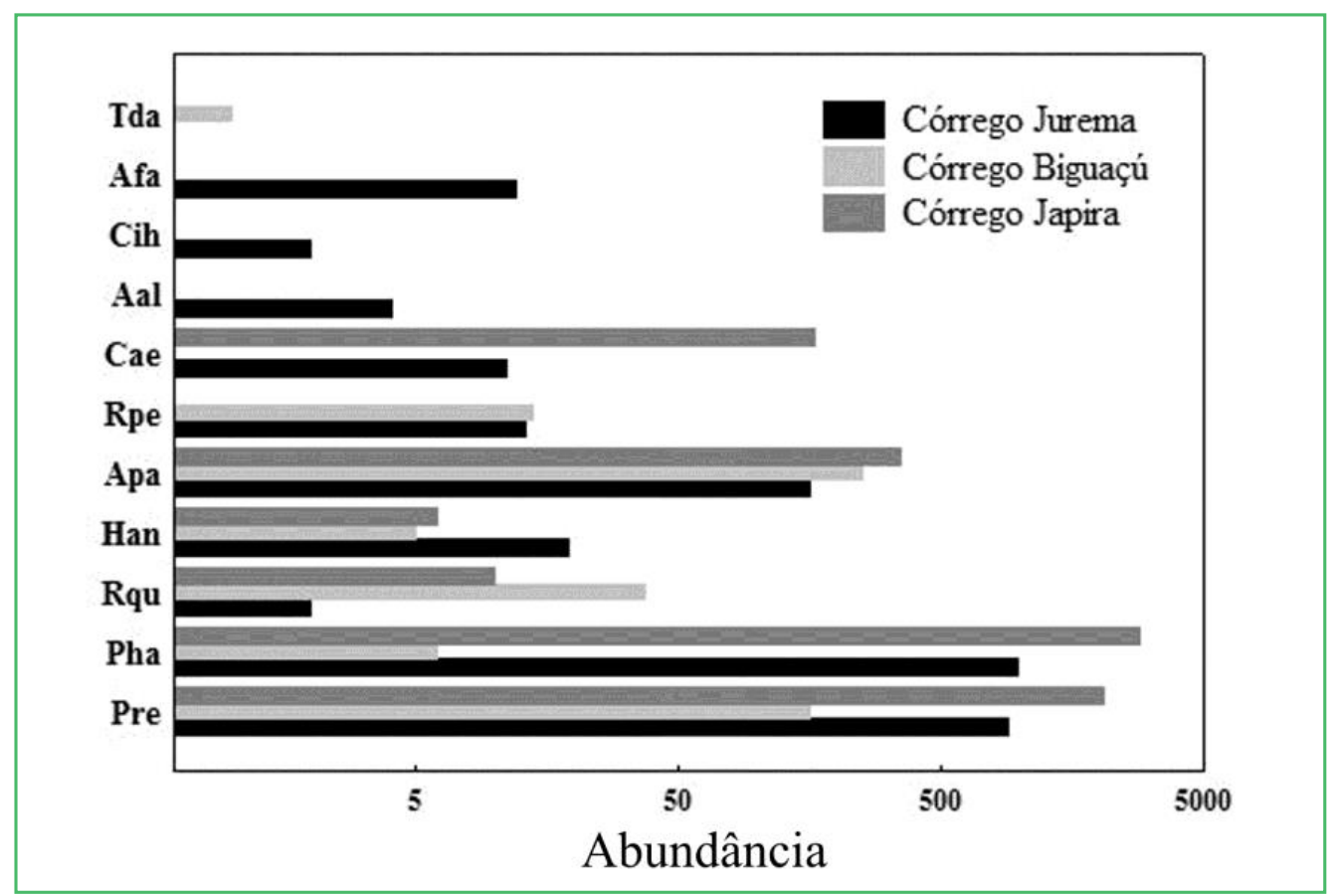


FIGURA 3: Curva de rarefação com distribuição de valores de riqueza de espécies para os córregos Jurema, Biguaçú e Japira.

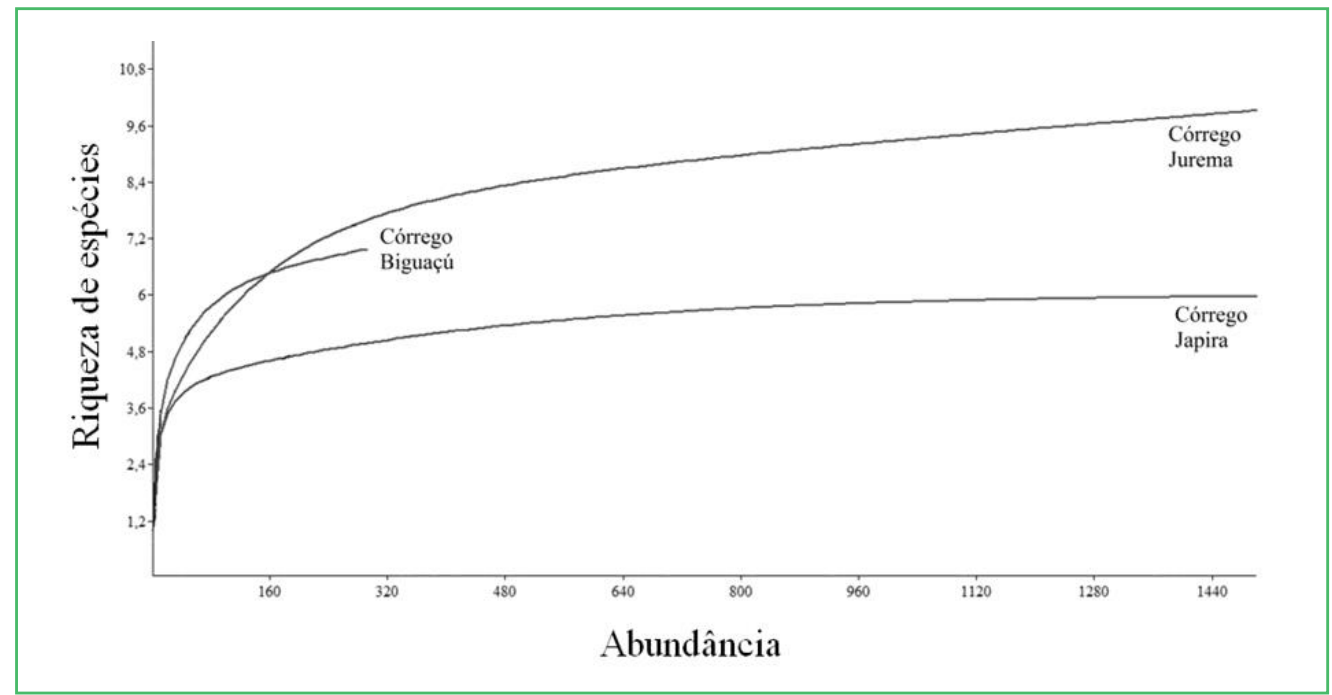

FIGURA 4: Valores dos índices ecológicos de Diversidade de espécies de Shannon (H'), Equitabilidade de Shannon (J) e Dominância de Simpson $(l)$, nos córrego Jurema, Biguaçú e Japira.

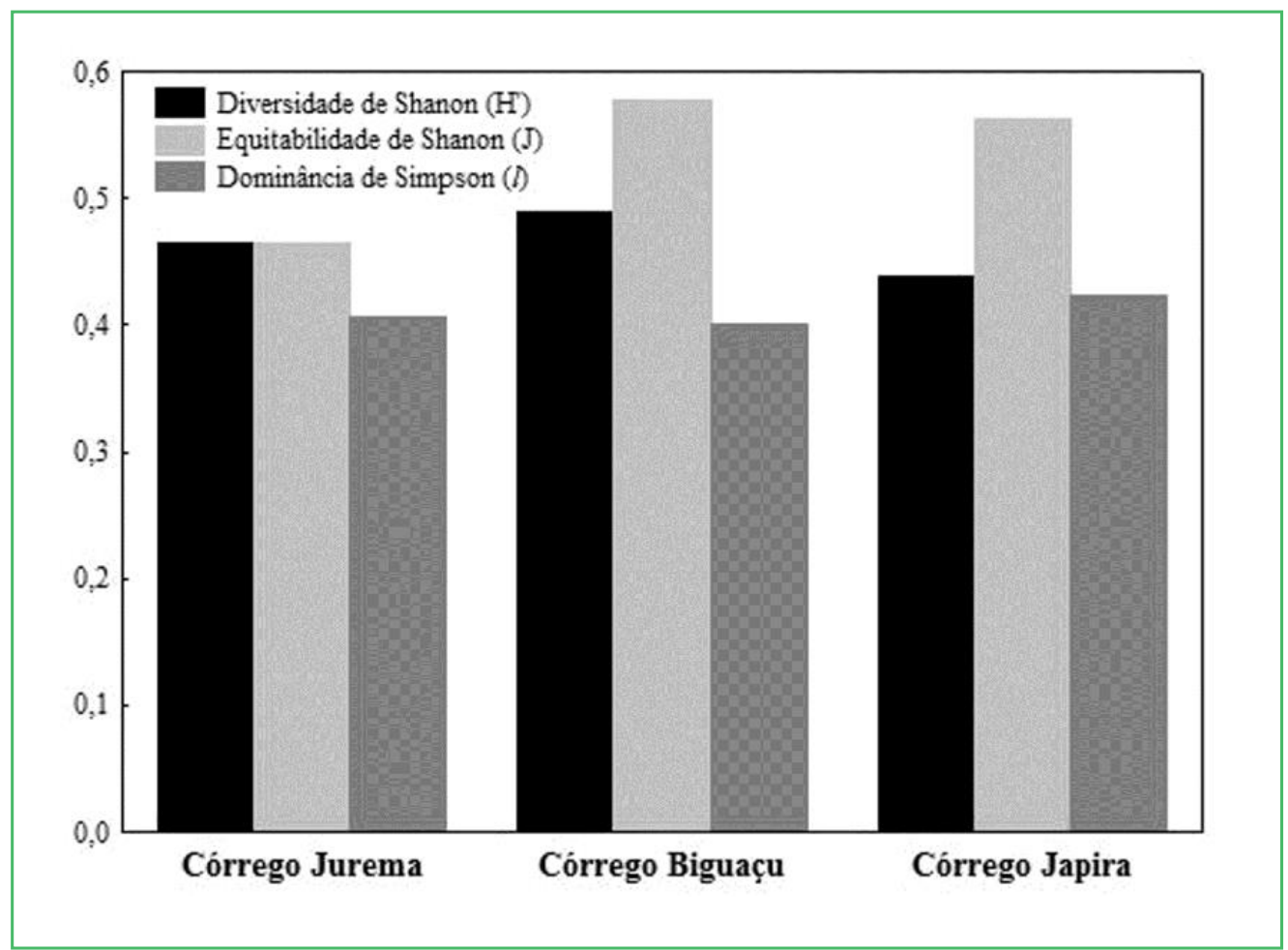

Ao analisar a similaridade da assembleia de peixes dos três córregos, pode-se dizer que os córregos Jurema e Japira são mais semelhantes, pois ambos apresentaram maior distância do córrego Biguaçú (Figura 5). 
FIGURA 5: Similaridade de Jaccard de espécies entre os córregos Jurema, Biguaçú e Japira.

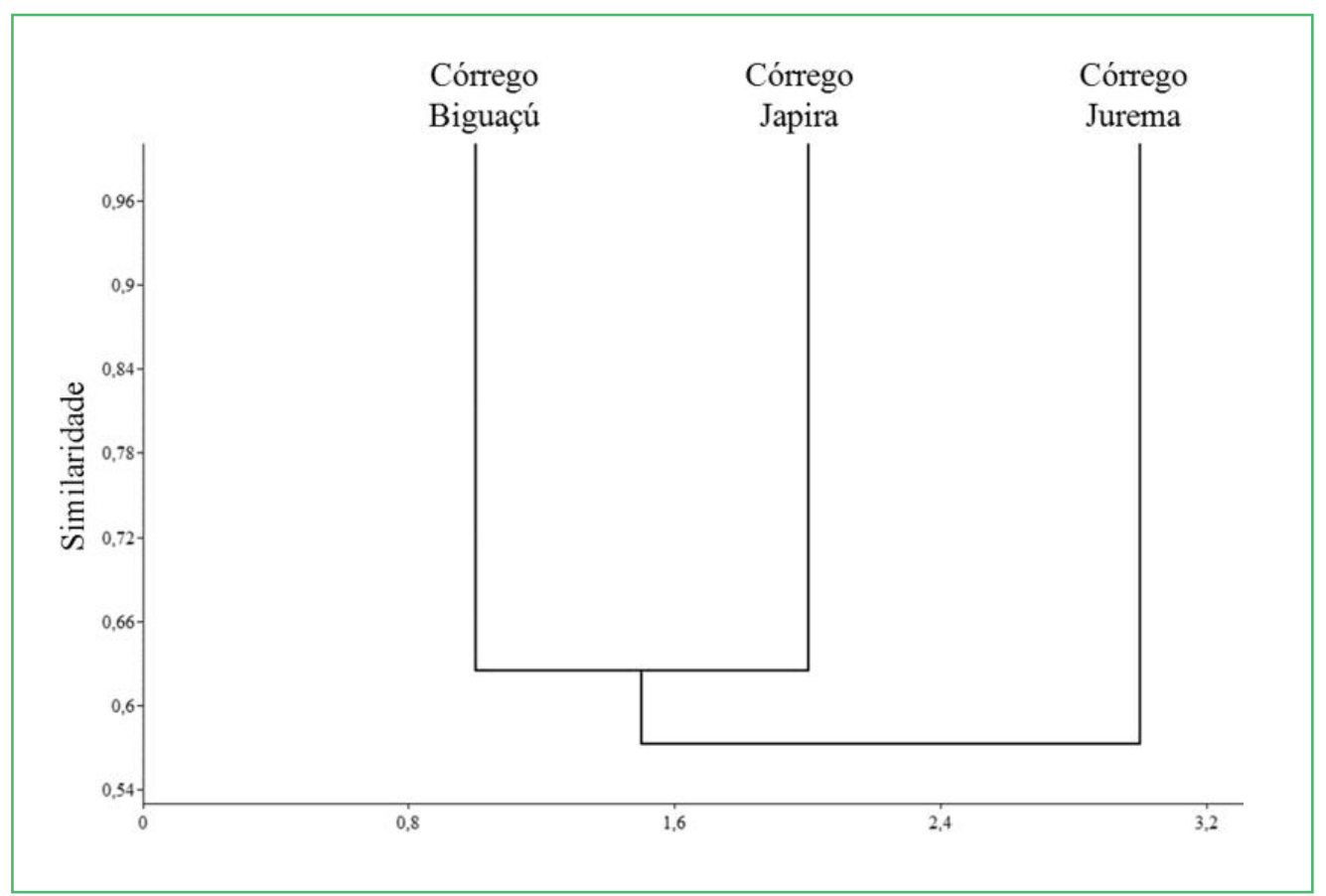

\section{Discussão}

A presença de altos valores nos índices de dominância de espécies e baixos valores na diversidade, equitabilidade e riqueza de espécies junto com a baixa qualidade de hábitats apresentados no córrego Japira, diferentemente dos córregos Jurema e Biguaçú, podem ser indícios de má conservação do local, principalmente devido a grande quantidade de residências na área de entorno, que pode favorecer a degradação da complexidade ambiental do córrego, de acordo com Galdean et al. (2000), a biodiversidade de um local tem relações intimas com o ambiente, principalmente quanto a disponibilidade de hábitats.

Além disso, estes dados podem ser relacionados com a grande abundância e dominância de $P$. reticulata neste ambiente, pois o aumento da densidade da população desta espécie, de acordo com Reznick et al. (2011) pode ser reflexo da falta de predadores naturais (principalmente por ser uma espécie exótica) e uma resposta a mudança drásticas no ambiente, no qual estes fatores dificultam o controle sobre crescimento desta população adaptada a ambientes extremos.
Constatamos que as espécies nativas nos córregos apresentaram maior abundância, biomassa total e dominância em relação às exóticas, representadas aqui pela $P$. harpagos e $A$. aff. paranae (nativas), no entanto, a ocorrência de espécies exóticas, como $P$. reticulata, pode ser considerada uma indicação da perda de integridade ambiental nestes riachos, o que pode levar à competição e sobreposição de nicho entre as espécies $P$. harpagos e $P$. reticulata (VIEIRA; SHIBATTA, 2007). Além disso, estas influências no uso de recursos e ocupação de hábitats podem ser amplificadas por possuírem características morfológicas semelhantes (NORTON et al. 1995), como por exemplo, a capacidade de suportar variações extremas que ocorrem no ambiente, principalmente por serem capazes de obter oxigênio da camada superficial d'água (BOOCK; MACHADO NETO, 2005).

Além do fator característico da qualidade ambiental de cada ambiente, outro fator presente muito importante observado foi à ocorrência de espécies semelhantes nos diferentes córregos, este fator pode ter relação com a geografia da cidade de Apucarana, que divide estes córregos em bacias diferentes. De acordo com Manosso (2007) o município de Apucarana tem 
características de um tríplice divisor de águas, dividindo pequenas bacias hidrográficas. Com isso, os resultados observados mostram que metade das espécies coletadas nos córrego co-ocorrem entre os ambientes, mesmo sendo de bacias hidrográficas diferentes, isto pode ser relacionado com a hidrodinâmica das bacias, de que se as espécies são comuns na bacia toda devem ser comuns nas microbacias que a compões, e a captura de cabeceiras destes corpos hídricos, que sofrem alterações marcantes nos níveis d'água afetando diretamente a disponibilidade de hábitats e variações na abundância de espécies, promovendo a dispersão de organismos entre os ambientes (RODRIGUES; LEWIS, 1994).

Porém, mesmo com a forte influência da dinâmica do ambiente, este evento não explica isoladamente o porquê algumas espécies só ocorreram em apenas um córrego, como é o caso de T. davisi no córrego Biguaçú e $A$. altiparanae, $C$. Iheringi e $A$. fasciatus no córrego Jurema. Este fato pode ser atribuído à existência de uma relação entre a distribuição das espécies e as características geomorfológicas do local. Winemiller e Willis (2011) afirmam que estas barreiras biogeográficas também podem influenciar diretamente a distribuição das espécies, principalmente em peixes de pequeno porte. Castro (1999) enfatiza, que estes organismos não possuem grande capacidade de deslocamento, por isso não fazem migrações extensas entre bacias hidrográficas durante a vida, com isso o grau de endemismo pode ser elevado entre estas populações, isolando-as nestes locais. Entretanto, Allan e Castillo (2007) comentam que além das características singulares de um ambiente, deve-se também levar em conta as características biológicas de cada organismo, como habilidade individual de dispersão, capacidade de colonização e os tipos de interações que estes organismos realizam.

No entanto, fica evidente uma correlação entre a ocorrência de espécies nos córregos e a qualidade ambiental com os índices ecológicos. Observa-se que o córrego Japira, em relação aos outros córregos amostrados, possui baixa riqueza e baixa qualidade ambiental, e concomitantemente a isso há um alto grau de co-ocorrência de suas espécies com os outros córregos e maiores valores no índice de dominância de espécies, pois todas as espécies coletadas neste córrego, também foram coletadas em pelo menos um dos outros córregos amostrados. Em contrapartida o córrego Jurema apresentou determinadas espécies exclusivas, com menores valores no índice de dominância e no grau de co-ocorrência, e ao mesmo tempo uma alta riqueza e alta qualidade ambiental em relação aos outros córregos. Estas características observadas podem assumir um grande papel no monitoramento da qualidade ambiental de corpos hídricos. De acordo com Luiz et al. (2005), estes fatores podem ser correlacionados para analisar a qualidade da estrutura de uma comunidade, especialmente porque estes parâmetros possuem grandezas inversamente proporcionais.

A relação entre qualidade ambiental e parâmetros ecológicos foi verificada indicando que medidas de restauração da qualidade destes ambientes aquáticos devem ser tomadas, como ações de reestruturação de mata ciliar e aplicação de programas em educação ambiental, que devem estar presentes nos planos gerenciadores do município, especialmente por se tratar de ambientes de cabeceiras de três importantes rios, para recuperação e preservação ambiental destas áreas.

\section{Agradecimentos}

Agradecemos à Fundação Araucária, CNPq, à Coleção Ictiológica do Núcleo de Pesquisa em Limnologia, Ictiologia e Aquicultura (Nupélia) e à Universidade Estadual de Maringá. Souza F. agradece ao Programa de Pós-Graduação em Biologia Comparada.

\section{Referências}

ALBERT, J. S.; REIS, R. E. Historical Biogeography of Neotropical Freshwater Fishes. Berkeley- Los AngelesUniversity of California Press, London, England, 2011, 389p.

ALLAN, J. D.; CASTILLO, M. M. Stream of ecology: structure and function of running waters. 2 ed. Dordrecht: Ed. Springer, 2007. 429 p.

BARRELLA, W.; PETRERE, M. JR. Fish community alterations due to pollution and damming in Tietê and Paranapanema rivers. River Research and Applications, Chichester, v. 19, p. 59-76, 2003. 
BENNEMANN, S. T.; SHIBATTA, O. A.; GARAVELLO, J. C. Peixes da bacia do rio Tibagi: uma abordagem ecológica. Londrina: EDUEL, 2000. 595 p.

BOOCK, M. V.; MACHADO NETO, J. G. Estudo sobre toxicidade aguda de oxicloreto de cobre para o peixe Poecilia reticulata. Boletim do Instituto de Pesca, São Paulo, v. 31, n. 1, p. 29-35, 2005.

CALLISTO, M.; FERREIRA, W. R.; MORENO, P.; GOULART, M.; PETRICIO, M. Aplicação de um protocolo de avaliação rápida da diversidade de habitats em atividades de ensino e pesquisa (MGRJ). Acta Limnologica Brasiliensia, São Carlos, v. 14, n. 1, p. 91 98, 2002.

CASTRO, R. M. C. Evolução da ictiofauna de riachos sulamericanos: padrões gerais e possíveis processos causais. In: CARAMASCHI, E. P.; MAZZONI, R.; PERES-NETO, P. R. (Ed.). Ecologia de peixes de riachos. Série Oecologia brasiliensis. Vol. VI. Rio de Janeiro: PPGR-UFRJ, 1999. p. 139-155.

CASTRO, R. M. C.; MENEZES, N. A. Estudo diagnóstico da diversidade de peixes do estado de São Paulo. In: JOLY, C. A.; BICUDO, C. E. M. (Ed.). Biodiversidade do Estado de São Paulo, Brasil: síntese do conhecimento ao final do século XX, 6: vertebrados. São Paulo: WinnerGraph, 1998. p. 1-13.

ESCHMEYER, W. N. Catalog of fishes. Special Publication. Vol. 3. San Francisco: California Academy of Sciences, 1998. 2905 p.

GALDEAN, N.; CALLISTO, M.; BARBOSA, F. A. R.; ROCHA, L. A. Lotic ecosystems of Serra do Cipó, southeast Brazil: water quality and a tentative classifications based on the benthic macroinvertebrate community. Journal of Aquatic Ecosystem Health and Management, Ontario, v. 3, p. 545-552, 2000.

GRAÇA, W. J.; PAVANELlI, C. S. Peixes da planície de inundação do alto rio Paraná e áreas adjacentes. Maringá: EDUEM, 2007. 241 p.

HAMMER, O.; HARPER, D. A. T.; RYAN, P. D. PAST: Paleontological Statistic software package for education and data analysis. Palaeontologia Electronica, Oslo, v. 4, n. 1, p. 9, 2001.

KARR, J. R. Assessment of biotic integrity using fish communities. Fisheries, Bethesda, v. 6, n. 6, p. 21-27, 1981.

LÉVÊQUE, C.; OBERDORFF, T.; PAUGY, D.; STIASSNY, M . L. J.; TEDESCO, P. A. Global diversity of fish (Pisces) in freshwater. Hydrobiologia, v. 595, p. 545-567, 2008.

LOWE-MCCONNELL, R. H. Estudos ecológicos de comunidades de peixes tropicais. São Paulo: EDUSP, 1999. 534 p.
LUIZ, E. A.; PETRY, A. C.; PAVANELLI, C. S.; JÚNIOR J.; HORACIO FERREIRA, L.; DIRÇO, J.; DOMINGUES, V. M. As assembléias de peixes de reservatórios hidrelétricos do estado do Paraná e bacias limítrofes. In: RODRIGUES, L.; THOMAZ, S. M.; AGOSTINHO, A. A.; GOMES, L. C. (Ed.). Biocenoses em reservatórios padrões espaciais e temporais. São Carlos: Ed RiMa, 2005. p. 107-113.

MANOSSO, F. C. Geoturismo: uma proposta teórica-metodológica a partir de um estudo de caso no município de Apucarana-Pr. Caderno Virtual de Turismo, Rio de Janeiro, v. 7, n. 2, p. 48-50, 2007.

MIRANDE, J. M. Phylogeny of the family Characidae (Teleostei: Characiformes): from characters to taxonomy. Neotropical Ichthyology, Porto Alegre, v. 8, n. 3, p. 385-568, 2010.

NORTON, S. F.; LUCZKOVICH, J. J.; MOTTA, P. J. The role of ecomorphological studies in the comparative biology of fishes. Environmental Biology of Fishes, Dordrecht, v. 44, p. 287-304, 1995.

REIS, R. E.; KULLANDER, S. O.; FERRARIS JUNIOR, C. J. (Org.) Check list of the freshwater fishes of South and Central America. Porto Alegre: EDPUCRS, 2003. 742 p.

REZNICK, D. N.; BASSAR, R. D.; TRAVIS, J.; RODD, H. Life history evolution in guppies VIII: the demographics of density regulation in guppies (Poecilia reticulata). Evolution, New York, v. 66, n. 9 , p. $2903-2915,2011$

RODRIGUES, W. C.; DivEs - Diversidade de espécies. Versão 2.0. Software e Guia do Usuário, 2005. Disponível em <http://www. ebras.bio.br/dives>. Acesso em: 22 abril 2009.

RODRÍGUEZ, M. A.; LEWIS, W. M. JR. Regulation and stability in fish assemblages of neotropical floodplain lakes. Oecologica, Porto Alegre, v. 99, p. 166-180, 1994.

RODRIGUES, A. S. L.; MALAFAIA, G.; CASTRO, P. T. A importância da avaliação do habitat no monitoramento da qualidade dos recursos hídricos: uma revisão. SaBios: Revista de Saúde e Biologia, Campo Mourão, v. 5, n. 1, p. 26-42, 2010.

VIEIRA, D. B.; SHIBATTA, O. A. Peixes como indicadores da qualidade ambiental do ribeirão Esperança, município de Londrina, Paraná, Brasil. Biota Neotropica, Campinas, v. 7, n. 1, p. 57-67, 2007.

WINEMILLER , K. O.; WILLIS, S. C. The Vaupes Arch and Casiquiare Canal: barriers and passages. In: ALBERT, J. S.; REIS, R. E. (Ed.). Historical biogeography of neotropical freshwater fishes. Berkeley: University of California Press Ltd., 2011. p. $225-$ 242. 